\title{
The influence of postoperative infection in survival of patients with high-grade gliomas
}

\author{
George A. Alexiou ${ }^{1}$, Amalia Kallinteri ${ }^{2}$, Euaggelos Michos ${ }^{1}$, Panagiota Zagorianakou ${ }^{1}$, Efthalia Priavali², \\ Dimitrios Pachatouridis ${ }^{1}$, Stamatina Levidiotou ${ }^{2}$, Spyridon Voulgaris ${ }^{1}$ \\ ${ }^{1}$ Department of Neurosurgery, Medical School, University of Ioannina, 45110 Ioannina, Greece. \\ ${ }^{2}$ Department of Microbiology, Medical School, University of Ioannina, 45110 Ioannina, Greece.
}

\section{A B S T R A C T}

High-grade gliomas are the most common type of brain tumors. Of these, glioblastoma account for $60-70 \%$ and despite treatment carries a dismal prognosis. Postoperative surgical site infection has been associated with prolonged survival. Herewith, we present a case of glioblastoma and a case of anaplastic oligoastrocytoma that developed postoperative infection of the surgical site and had prolonged survival. A thorough literature review is also presented.

Key words: Glioblastoma, high-grade glioma, infection, survival

\section{INTRODUCTION}

High-grade gliomas are the most common type of primary brain tumors and carry a dismal prognosis..$^{[1]}$ Glioblastoma is by far the most common type occurring in adults. This devastating disease is usually incurable and despite aggressive treatment the median survival time remains in the range of 15 months. ${ }^{[1]}$ Median survival for anaplastic tumors is usually 2-3 years with anaplastic oligodendroglioma having a better survival. ${ }^{[2]}$ There have been reports that patients with postoperative infection of the craniotomy site experienced long term survival. ${ }^{[3,4]}$ Herewith, we report on two cases of high-grade gliomas with confirmed postoperative infection and prolong survival.

\section{CASE REPORT}

Case 1

A 48-year-old woman underwent a brain magnetic resonance imaging (MRI) because of persisted headache and dizziness. A left frontal lesion $(4.2 \mathrm{~cm} \times 3.7 \mathrm{~cm} \times 5 \mathrm{~cm})$ with prominent peri-focal edema and mass effect was revealed. The lesion

\begin{tabular}{|l|l|}
\hline \multicolumn{2}{|c|}{ Access this article online } \\
\hline Quick Response Code: & \\
\hline & Website: \\
\hline & www.nnjournal.net \\
\cline { 2 - 3 } & DOI: \\
\hline
\end{tabular}

enhanced after gadolinium administration, The Karnofsky performance scale (KPS) score was 100. The patient underwent a left frontal craniotomy with radical resection of the lesion. Histological examination revealed the presence of a glioblastoma. The postoperative KPS at the time of discharge was 100. The patient received concomitant temozolomide (TMZ) with radiotherapy (60 Gy) followed by adjuvant TMZ. Eleven months later the patient had a generalized seizure. Follow-up MRI revealed a lesion suspicious of tumor recurrence. Brain single-photon emission computed tomography (SPECT) with ${ }^{99 m}$ Tc-tetrofosmin demonstrated increased tracer uptake suggesting tumor recurrence. The patient was re-operated, and carmustine wafers were placed around the resection cavity. The postoperative period was uneventful, and the patient was discharged home on the 7th postoperative day. One week later the patient was hospitalized because of discharge from the surgical wound. Wound cultures were obtained. Identification and antimicrobial susceptibility of the microorganisms were performed by the automatized VITEK 2 System (BioMerieux, France). The results showed the presence of Staphylococcus haemolyticus (coagulase-negative Staphylococcus, CoNS) resistant to penicillin, oxacillin, levofloxacin, moxifloxacin and gentamycin. The patient received proper antibiotic treatment, and the infection was resolved. The patient remained free of disease for 27 months when recurrence was noted on follow-up MRI. Anti-VEGF treatment was administered; however, she died 3 months later. Her overall survival was 42 months.

Corresponding Author: Dr. George A. Alexiou, Department of Neurosurgery, Medical School, University of loannina, 45110 loannina, Greece. E-mail: alexiougrg@yahoo.gr 
Case 2

A 22-year-old man underwent a brain MRI because of seizures. The MRI revealed a $5 \mathrm{~cm} \times 3.2 \mathrm{~cm} \times 4.3 \mathrm{~cm}$ left frontal lesion. The lesion had a heterogeneous cystic and solid appearance that enhanced after gadolinium administration. The patient underwent surgical resection, and gross total excision was performed. Histological examination revealed the presence of an astrocytoma Grade II. Postoperative radiation treatment was administered. On follow-up MRI 7 years later a lesion suspicious for tumor recurrence was noted. The patient was re-operated, and the histology revealed the presence of an anaplastic oligoastrocytoma. The patient received TMZ-based chemotherapy. Nevertheless, 28 months later the patient had uncontrolled seizures. Brain MRI demonstrated a lesion suspicious of tumor recurrence. Brain SPECT with ${ }^{99 \mathrm{~m} T c-t e t r o f o s m i n}$ was positive for recurrent disease. The patient was re-operated. A new recurrence was noted 23 months later, and the patient re-operated, carmustine wafers were placed around the resection cavity. Postoperatively, the patient had fever and discharge from the wound. Brain CT showed findings consistent with infection and there was contrast enhancement. The patient was re-operated, and craniectomy was performed. Cerebrospinal fluid cultures showed the presence of Staphylococcus epidermidis (CoNS) resistant to penicillin, oxacillin, erythromycin and clindamycin. After proper antibiotic treatment, the patient improved. The patient did not show any sign of the tumor reappearance for 37 months until recurrence was noted. Two months later he died. The overall survival was 14 years.

\section{DISCUSSION}

High-grade gliomas are the most common brain tumors in adults and are highly malignant. ${ }^{[2]}$ Treatment includes surgery, postoperative radiotherapy, and concomitant and adjuvant chemotherapy. ${ }^{[2]}$ Nevertheless, even receiving the same treatment, the clinical outcome of patients varies significantly. ${ }^{[1]}$ Age, 1p19q deletion status and isocitrate dehydrogenase (IDH) mutational status are of prognostic significance..$^{[5,6]}$

A survival benefit for patients that developed postoperative infection in the tumor removal site has been reported..$^{[3,4]}$ Postoperative infection is generally considered when wound and/or bone flap infection, cerebral abscess, or meningitis, occur within 2 months from surgery. ${ }^{[2]}$ Its incidence has been reported to range between $0.75 \%$ and $2.3 \%$ for intracranial operations. ${ }^{[7]}$ De Bonis et al. studied 197 patients operated for glioblastoma and found 10 cases of postoperative bacterial infection. Patients that developed infection had a median survival of 30 months whereas patients without postoperative infection had a median survival of 15 months. The difference was statistical significant. In 5 cases there was a surgical abscess, in 3 cases abscess and wound infection and in 2 cases surgical wound and bone flap infection required surgical revision. In 6/10 cases Staphylococcus aureus was isolated. ${ }^{[2]}$ In the present study, the patient with glioblastoma had an overall survival of 42 months. In a previous study in our institute, the median survival of patients with glioblastoma was 15.5 months. ${ }^{[8]}$ Bowles et al. also reported 4 cases of malignant brain tumors with prolonged survival after postoperative infection. In those cases, Enterobacter aerogenes was isolated. The authors suggested that in addition to the bacteria direct oncolytic effect, an immune adjuvant responses to tumor suppression might play a role. ${ }^{[4]}$ Nevertheless, Bohman et al. did not find a survival advantage in 18 patients with postoperative infection after glioblastoma resection out of 382 patients included in their study. ${ }^{[9]}$

Regarding experimental data, a recent study showed that intracerebrally implanted heat-inactivated staphylococcal epitopes mixed with 9L gliosarcoma cells in Wistar rats, resulted in significant prolong survival than controls. In one case there was complete regression of an already grown mass. ${ }^{[10]}$ William Coley, a pioneer in immunotherapy, was the first injecting a mixture of live streptococcus bacilli and subsequently heat-killed Streptococcus into tumors and managed to induce remission of inoperable sarcomas. ${ }^{[11]}$ This vaccine was also successful in cases of melanoma and lymphomas. ${ }^{[12]}$ According to Coley, the induction of fever was a key element. ${ }^{[12]}$ The inflammation cascade induced by bacteria and the presence of factors such as interferon-alpha, tumor necrosis factor-alpha, interleukin-2, have been considered as the cause of this effect. ${ }^{[12]}$ Tanaka et al. injected intratumorally an immunopotentiator, Picibanil, in 13 patients with brain tumors. ${ }^{[13]}$ Picianil was a low virulent mutant strain of Lancefield's Type 111, Group A Streptococcus pyogenes. The results showed significant tumor regression in 6/12 patients for whom CT was performed. ${ }^{[13]}$ More recently, Jeys et al. investigated the effect of postoperative infection in patients treated for osteosarcoma, using endoprosthetic replacement and neo-adjuvant chemotherapy. The results showed that patients who developed an infection had a significantly longer survival. Furthermore, infection was an independent prognostic factor on cox regression analysis. ${ }^{[14]}$ Ruckdeschel et al. reported improved survival rates for patients who developed the empyema after lung cancer compared with noninfected patients. ${ }^{[15]}$ 
In the present study, both patients were treated at recurrence with carmustine wafers that were placed around the resection cavity. Carmustine wafers have been shown to yield better survival rates of 1-2 months in primary high-grade gliomas. ${ }^{[16]}$ Thus, the prolonged survival of both patients cannot be attributed to the implanted wafers.

In conclusion, the role of infection provides a rationale for further research in cancer treatment. Certainly, there is a need for larger studies that may provide more accurate answers. This may also lead to a subgroup analysis that would better define if patients survival is influenced by bacterial strain, location of the infection or time to infection.

\section{REFERENCES}

1. Liu Y, Shete S, Etzel CJ, Scheurer M, Alexiou G, Armstrong G, Tsavachidis S, Liang FW, Gilbert M, Aldape K, Armstrong T, Houlston R, Hosking F, Robertson L, Xiao Y, Wiencke J, Wrensch M, Andersson U, Melin BS, Bondy M. Polymorphisms of LIG4, BTBD2, HMGA2, and RTEL1 genes involved in the double-strand break repair pathway predict glioblastoma survival. J Clin Oncol 2010;28:2467-74.

2. Nuño M, Birch K, Mukherjee D, Sarmiento JM, Black KL, Patil CG. Survival and prognostic factors of anaplastic gliomas. Neurosurgery 2013;73:458-65.

3. De Bonis P, Albanese A, Lofrese G, de Waure C, Mangiola A, Pettorini BL, Pompucci A, Balducci M, Fiorentino A, Lauriola L, Anile C, Maira G. Postoperative infection may influence survival in patients with glioblastoma: simply a myth? Neurosurgery 2011;69:864-8.

4. Bowles AP Jr, Perkins E. Long-term remission of malignant brain tumors after intracranial infection: a report of four cases. Neurosurgery 1999;44:636-42.

5. Cairncross JG, Wang M, Jenkins RB, Shaw EG, Giannini C, Brachman DG, Buckner JC, Fink KL, Souhami L, Laperriere NJ, Huse JT, Mehta MP, Curran WJ, Jr. Benefit from procarbazine, lomustine, and vincristine in oligodendroglial tumors is associated with mutation of IDH. J Clin Oncol 2014;32:783-90.

6. Panageas KS, Reiner AS, Iwamoto FM, Cloughesy TF, Aldape KD, Rivera AL, Eichler AF, Louis DN, Paleologos NA, Fisher BJ, Ashby LS, Cairncross JG, Roldan Urgoiti GB, Wen PY, Ligon KL,
Schiff D, Robins HI, Rocque BG, Chamberlain MC, Mason WP, Weaver SA, Green RM, Kamar FG, Abrey LE, DeAngelis LM, Jhanwar SC, Rosenblum MK, Lassman AB. Recursive partitioning analysis of prognostic variables in newly diagnosed anaplastic oligodendroglial tumors. Neuro Oncol 2014;16:1541-6.

7. Miller JT, Rahimi SY, Lee M. History of infection control and its contributions to the development and success of brain tumor operations. Neurosurg Focus 2005;18:e4.

8. Alexiou GA, Goussia A, Voulgaris S, Fotopoulos AD, Fotakopoulos G, Ntoulia A, Zikou A, Tsekeris P, Argyropoulou MI, Kyritsis AP. Prognostic significance of MRP5 immunohistochemical expression in glioblastoma. Cancer Chemother Pharmacol 2012;69:1387-91.

9. Bohman LE, Gallardo J, Hankinson TC, Waziri AE, Mandigo CE, McKhann GM 2nd, Sisti MB, Canoll P, Bruce JN. The survival impact of postoperative infection in patients with glioblastoma multiforme. Neurosurgery 2009;64:828-34.

10. Löhr M, Molcanyi M, Poggenborg J, Spuentrup E, Runge M, Röhn G, Hartig W, Hescheler J, Hampl JA. Intracerebral administration of heat-inactivated Staphylococcus epidermidis enhances oncolysis and prolongs survival in a 9L orthotopic gliosarcoma model. Cell Physiol Biochem 2013;31:614-24.

11. Decker WK, Safdar A. Bioimmunoadjuvants for the treatment of neoplastic and infectious disease: coley's legacy revisited. Cytokine Growth Factor Rev 2009;20:271-81.

12. Tanaka R, Sekiguchi K, Suzuki Y, Sobue H, Ueki K. Preliminary evaluation of intratumoral injection of a Streptococcus pyrogenes preparation in patients with malignant brain tumors. Cancer 1980;46:1688-94.

13. Hoption Cann SA, van Netten JP, van Netten C. Dr William Coley and tumour regression: a place in history or in the future. Postgrad Med J 2003;79:672-80.

14. Jeys LM, Grimer RJ, Carter SR, Tillman RM, Abudu A. Post operative infection and increased survival in osteosarcoma patients: are they associated? Ann Surg Oncol 2007;14:2887-95.

15. Ruckdeschel JC, Codish SD, Stranahan A, McKneally MF. Postoperative empyema improves survival in lung cancer. Documentation and analysis of a natural experiment. N Engl J Med 1972;287:1013-7.

16. Bregy A, Shah AH, Diaz MV, Pierce HE, Ames PL, Diaz D, Komotar RJ. The role of Gliadel wafers in the treatment of high-grade gliomas. Expert Rev Anticancer Ther 2013;13:1453-61.

Cite this article as: Alexiou GA, Kallinteri A, Michos E, Zagorianakou P, Priavali E, Pachatouridis D, Levidiotou S, Voulgaris $S$. The influence of postoperative infection in survival of patients with high-grade gliomas. Neuroimmunol Neuroinflammation 2015;2(1):18-20.

Source of Support: Nil. Conflict of Interest: No.

Received: 19-08-2014; Accepted: 01-09-2014 